\title{
Projecting Changes to Coastal and Estuarine Ecosystem Goods and Services-Models and Tools
}

\author{
Nathaniel S. Lewis, Darryl E. Marois, Chanda J. Littles, \\ and Richard S. Fulford
}

\begin{abstract}
Coasts and estuaries provide an abundance of ecosystem goods and services (EGS) to humans worldwide. Models that track the supply, demand, and change in EGS within these ecosystems provide valuable insights that have applications in the context of land-use planning, decision-making, and coastal community engagement. However, developing models for use in coastal and estuarine ecosystems is challenging given the multitude and variability of potential input variables, largely due to their dynamic nature and extensive use. Models that can incorporate scenarios of environmental change to forecast changes in EGS endpoints are highly valuable to decision-makers, but only a minor proportion of available EGS models offer this utility. In this chapter, we describe the domain of models most useful to coastal decision-makers, present models at multiple scales that can predict EGS changes, and examine specific examples that epitomize this utility. We also highlight common difficulties in modeling coastal and estuarine EGS and propose suggestions for integrating EGS models into the coastal management decision-making process during times of increasing environmental change.
\end{abstract}

\section{Lessons Learned}

- Identifying the most suitable model(s) given the scale(s) of a particular question or goal is paramount in the modeling process

- Uncertainty is an inherent component of modeling that should be wellcommunicated by users to avoid misinterpretation of results

\footnotetext{
N. S. Lewis $(\bowtie) \cdot$ D. E. Marois

Pacific Ecological Systems Division, U.S. Environmental Protection Agency, Newport, OR, USA

e-mail: nate.lewis@oregonstate.edu

C. J. Littles

Environmental Resources Branch, U.S. Army Corps of Engineers, Portland, OR, USA

R. S. Fulford

US Environmental Protection Agency, Gulf Ecosystem Measurement and Modeling Division, Gulf Breeze, FL, USA
} 
- The complexity, as well as the time, cost, and data requirements, of many EGS models are barriers to widespread implementation

\section{Needs to advance EBM}

- To improve model relevancy and usability, resource managers and other stakeholders must be part of the model development process to identify important decision metrics

- Tiered or coupled models can allow for the identification and inclusion of multiple drivers as well as cumulative impacts on coastal and estuarine EGS, which is a critical need

- Development of a standardized framework for model implementation would increase the adoption of EGS models into coastal and marine planning processes

\section{Modeling Changes in Coastal and Estuarine EGS}

Coastal and estuarine ecosystems host some of the most dynamic and productive habitats in the world (Costanza et al. 1997; Costanza et al. 2014), including: seagrass beds, mangroves, coral reefs, salt marshes, sandy beaches, and dunes (Barbier et al. 2011). Each of these habitats provides a unique combination of benefits across the broad ecosystem goods and services (EGS) categories (i.e., provisioning, regulating, cultural, and supporting services) set forth by the Millennium Ecosystem Assessment (2005) (e.g., Marois and Mitsch 2015; Kassakian et al. 2017). As environmental changes propagate through these ecosystems, the provision of important EGS may also be affected. Changes can result from natural or anthropogenic impacts and come in a myriad of shapes and forms, including: sea-level rise, pollution, invasive species, storm events, and detrimental fishing practices.

Ecosystem alterations can be the product of a multitude of factors, occur at different spatiotemporal scales, and affect EGS of all types. Integrating these dynamic variables poses a challenge when modeling EGS endpoints. However, the quantity of models and tools that explicitly predict changes to EGS based on alterations to input variables make up a minor proportion of all models applied in coastal and estuarine ecosystems. Some of this disparity may be due to the relatively recent development of the EGS concept, as well as the inherent complexity and variability of these models. In this chapter, we present a suite of models that exemplify the approach of predicting EGS changes at different scales, outline the domain of models that may offer the most utility to coastal decision-makers, present examples epitomizing this utility, and highlight common difficulties across coastal and estuarine EGS models. We conclude with suggestions for integrating EGS models into the coastal management decision-making process during times of increasing environmental change.

Developing models for application in coastal and estuarine ecosystems can be challenging given their dynamic nature and the multitude of potential inputs and outputs; however, models provide valuable tools that can be used for many purposes, 
such as visualizing species distribution, assessing chemical fluxes, explaining habitat-species relationships, or identifying spatial patterns. The utility of models increases substantially for resource managers when environmental changes can be simulated within these tools to predict changes to EGS.

Although there are many EGS models (Bagstad et al. 2013b; Turner et al. 2016; Gret-Regamey et al. 2017; Little et al. 2017), this chapter focuses on models that provide predictions of how EGS may be affected as coastal ecosystems undergo change. We further narrow this focus to models that demonstrate a high degree of utility to decision-makers based on relevant spatial scales and endpoints. Within these criteria, we present example models that are well-established and demonstrate these traits with different degrees of complexity and quantities of modeled services to show the utility of this approach across a diverse spectrum of models.

Coastal and estuarine EGS models can range from simulating services provided by a specific site or habitat (Mendoza et al. 2017; Harris et al. 2018), to estimating global EGS values (Costanza et al. 1997; Boumans et al. 2015). Here, we limit our focus to models with spatial scales ranging from local (e.g., estuary or bay) to regional (e.g., U.S. Pacific West Coast), as they are the most likely to provide useful information when making resource management decisions (Turner et al. 2016). These models also vary greatly in their final output or endpoint. Some estimate relative changes in the degree of EGS provision (Hanson et al. 2012; Harris et al. 2018), while others estimate monetary values of EGS (Carr et al. 2018). The example models we discuss in this chapter all provide outputs that are quantitative and informative (but not necessarily monetary), as these provide the most benefit to decision-makers at local and regional scales (Ruckelshaus et al. 2015).

Within these established bounds of endpoint and spatial scale there still exists a wide range of model complexity. The spatial and/or temporal resolution, system dynamics considered, and type of EGS simulated each affect model complexity. In the following sections, we explore five example models representing different combinations of spatial scale, quantity of EGS, and complexity, each occupying different niches within the domain of EGS models that can predict change and inform decisions. The first model, HexSim, is a mechanistic model that describes living populations by tracking individuals; the second, $\mathrm{XBeach}$, is a mechanistic model for estimating shore protection; the third, Atlantis, is a whole system model used in fishery management; the fourth, InVEST, contains many sub-models that can predict delivery of a suite of EGS; and the fifth, ARIES, uses machine learning to trace ecosystem service flows to beneficiaries.

\section{HexSim Model}

Ecosystem services under management are frequently tied to changes in both the behavior and demographics of living resources. Predicting these changes is an important part of decision making, and object-oriented and Individual-Based Models (IBMs) play an important role, both in making these predictions and in 
operationalizing the answers as a tool for policy. IBMs are mechanistic models that have typically been used to evaluate the movement, growth, and mortality of living populations, by tracking individuals rather than the population as a whole (DeAngelis and Rose 1992). IBMs are complex by nature because they describe an individual's state, and therefore the spatial resolution of any input data must match individual behavior (e.g., meter), while ensuring the spatial scale of the model remains relevant to decision making (e.g., whole estuary). IBMs are inherently data intensive because the mechanistic descriptions of movement, feeding, growth, and mortality are all necessary to properly track a group of individuals. Yet, given sufficient input data, IBMs have proven useful for predicting population-level change, particularly in cases where average population conditions are not sensitive to management.

IBMs track the state and response of individual agents, then combine the outcomes into a population level distribution for the chosen response variable (e.g., total biomass, individual size). Agents are defined by the context of the question but are generally individual organisms of a population or demographic group (e.g., individual anglers). In spatially explicit cases, the agent can be a spatial grid cell as is the case in the HexSim IBM (Rustigian et al. 2003; Fulford et al. 2011). Such spatial models are optimized for the study of population distribution in response to heterogeneous landscapes. Input data must include initial agent state for key variables, as well as function parameters describing how agents respond to environmental variability and management-based change. IBMs are by nature an iterative suite of interconnected forcing functions. Model output is temporally and spatially explicit as the model tracks individual deviations from an initial state, which can be summarized at any time during a model simulation.

The HexSim model (Schumaker et al. 2004; Schumaker and Brookes 2018) was used to predict the impact of seagrass management on fishery resources in Tampa Bay (Fulford et al. 2016). Seagrass restoration was combined with a suite of other habitat components, including water temperature and hypoxia, to predict how individual habitat selection and subsequent growth were impacted. Management decisions were evaluated in the context of multiple environmental factors based on their cumulative impact on growth and production of aquatic resources that provide ecosystem services. The IBM also informed the delivery of ecosystem services to stakeholders in that individual angler behavior was modeled in response to changes in fish distribution and apparent availability of habitat as fishing grounds. This latter bioeconomic component of the model was based on angler preference data (Fulford et al. 2016).

HexSim in Tampa Bay was a coupled movement and bioenergetics model for fish and a coupled movement and fishing success model for anglers. Input data included fish distribution prior to habitat change, habitat-specific fish growth and movement functions, angler distribution, and an angler choice function based on distance from access points and daily fishery return. Fish moved first, and their growth and mortality were predicted based on habitat choice. Anglers chose fishing locations based on distance from access points and knowledge of optimal fishing habitat and 
their catch rate was predicted based on a probability model and predicted overlap between anglers and catchable fish (Fulford et al. 2016).

IBMs are most useful in cases where the mean output value is insensitive to manageable change in the system (e.g., habitat restoration). A good example is the mean fish growth rate in the Tampa recreational fishery in response to seagrass habitat restoration (Fulford et al. 2016). Compensatory behavior and the multifaceted nature of habitat selection greatly ameliorated the mean fish growth response, even with a large change in seagrass coverage. As a result of this insensitivity, the impact of successful seagrass restoration on fishery harvest was highly difficult to identify. As an alternative, an IBM approach was used to track individual behavioral response to habitat distribution, then bioenergetics sub-models were used to translate fish distribution into population production.

An IBM approach, such as the HexSim model described here, is both dataintensive and complicated enough that managers rarely attempt its application without assistance. That limits the utility of this approach to environmental decision making in data rich contexts (Rose et al. 2010; Rose et al. 2015). However, the availability of data and expertise for IBM use is higher than it has ever been and growing. These models require a high level of expertise to apply, yet the subtle nature of management related change and the confounding influence of other environmental variables make the use of IBMs much more informative and highly desirable for decision making.

\section{XBeach Model}

Models that can simulate the link between an ecosystem's structure and its ability to deliver ecosystem services are key to bridging the gap between ecology and economics. These types of models are often highly mechanistic and can occasionally be adapted for integration into tools for estimating coastal EGS (Bruins et al. 2017). XBeach is one such model that has been used to predict the ability of coral reefs to deliver the service of coastal protection under various conditions (Quataert et al. 2015; Pearson et al. 2017; Harris et al. 2018). It is a one-dimensional, morphodynamic model that simulates how ocean waves travel across complex, near-coast topographies and propagate up to the shore (Roelvink et al. 2009). XBeach was originally designed for wave propagation on beaches, but with some modification it has been expanded to simulate accurate reef hydrodynamics (Pomeroy et al. 2012; Van Dongeren et al. 2013). These capabilities allow it to estimate the extent to which coral reefs reduce wave run-up (how high a wave rises above mean sea level as it reaches the coastline) at local and regional scales. XBeach can also predict changes in the provision of reef shoreline protection under scenarios of environmental change such as sea level rise (Harris et al. 2018).

If a coral reef ecosystem is significantly diminished in size or health, its valuable coastal protection service could be completely lost (Sheppard et al. 2005). These protective services can also be reduced if coral reefs are not able to grow vertically at 
a rate comparable to rates of sea level rise (Harris et al. 2018). Within XBeach, reef degradation scenarios can be simulated by altering coastal bathymetry and surface roughness inputs, while sea level rise can be simulated by increasing offshore waveheight drivers. Resulting changes in the model output of wave run-up can then be interpreted from a coastal hazard perspective, with higher run-up values leading to a greater risk of damage to coastlines, particularly during storm events that further increase wave heights (Quataert et al. 2015).

Harris et al. (2018) demonstrated the utility of XBeach in predicting coastal protection services, by applying the model in reef sites in French Polynesia. Model parameters were calibrated using measured data from pressure loggers in cross-reef transects. They varied model inputs of sea level, reef vertical accretion or erosion, and reef surface roughness (corresponding to reef structural complexity). Monte Carlo simulations, in which the model was run multiple times with inputs varying randomly across a range of values, were used to address variability that was not captured by XBeach. Overall, results showed that the combined effects of sea level rise, reef erosion, and reduction in reef structural complexity led to wave heights that were 2.4 times greater than those under present conditions (Harris et al. 2018). These findings not only quantified the amount of protection offered by reefs under current conditions, but also provided coastal land managers with predictions of how waves may impact coastal areas in the future should the extent of coral reefs decline.

XBeach model output primarily consists of an estimated reduction in wave height, which by itself may not be informative enough for coastal decision-makers to draw worthwhile conclusions. However, when mechanistic models like XBeach are incorporated into larger modeling frameworks, its output can be used as an input for another model predicting levels of ecosystem service provision (Bagstad et al. 2013b). For example, the reduction in wave height could be converted into a reduced frequency of flooding, which may be more informative. Further, this reduction in flooding frequency could be converted into monetary value using methods similar to those described by Barbier (2016). This use of well-established and validated mechanistic models to deliver predictions of coastal EGS can be effective for incorporating EGS considerations into coastal management decisions and policy.

\section{Atlantis Model}

In whole-system (i.e., end-to-end) models (Travers et al. 2007), biophysical, socioeconomic, and industrial components and processes are considered, along with associated feedbacks and interactions between components (Fulton et al. 2011; Kaplan et al. 2012; Weijerman et al. 2015; Marshall et al. 2017). One such model is Atlantis, developed for use in Management Strategy Evaluation, it supports Ecosystem-Based Management (EBM) of multiple fisheries on a regional scale (Link et al. 2010; Fulton et al. 2011). Atlantis is a complex, spatially explicit, hierarchical model containing interconnected submodels to evaluate potential 
management actions, policy changes, and ecosystem tradeoffs under various scenarios (Kaplan et al. 2012; Fulton et al. 2014; Marshall et al. 2017).

A biophysical submodel is the primary submodel within Atlantis, which follows nutrient flows (primarily nitrogen and silica) and distribution through the food-web to large marine mammals via ecological processes (e.g., production, predation, recruitment) and physical features (e.g., hydrodynamics, seabed types, water properties) (Link et al. 2010; Fulton et al. 2011). Output data from the biophysical model feed into an exploitation submodel that considers human uses and impacts, such as fishing, pollution, development, and other environmental changes (Link et al. 2010; Fulton et al. 2011). A monitoring and assessment submodel then utilizes outputs from the biophysical and exploitation models to simulate scenarios, from which adaptive management options and the associated uncertainty can be assessed (Link et al. 2010; Fulton et al. 2011). Finally, the monitoring and assessment output is fed into a management submodel, which consists of potential management rules defined by the user (e.g., restrictions, quotas, limits) that respond to the inputs from the assessment model (Link et al. 2010; Fulton et al. 2011).

Endpoints of Atlantis can include metrics such as biomass, concentration, catch, effort, or revenue (Link et al. 2010; Fulton et al. 2011; Kaplan et al. 2012; Marshall et al. 2017). Marshall et al. (2017) built upon previous applications (Kaplan et al. 2012; Weijerman et al. 2015) and utilized Atlantis to project the impacts of ocean acidification scenarios on fisheries EGS in the California Current ecosystem. To achieve this, future $\mathrm{pH}$ projections and biological $\mathrm{pH}$ sensitivities were plugged into the biophysical submodel; $\mathrm{pH}$ projections were derived from a separate model, whereas $\mathrm{pH}$ sensitivities were obtained from a meta-analysis of experimental results (Busch and McElhany 2016). Results demonstrated that a projected 0.2-unit decrease in $\mathrm{pH}$ negatively affected biomass, catch, and resulting revenue of most fishery management units considered. Atlantis predicted that state-managed functional groups would experience the greatest $\mathrm{pH}$ effects on revenue, largely due to the strong indirect effects on the valuable Dungeness crab fishery.

Although the full capability of Atlantis is impressive, utilization of the entire model without identifying key drivers can lead to over-parameterization (Fulton et al. 2011). There is also an inherent tradeoff between generality and precision with this broad ecosystem-based approach (Plaganyi 2007; Link et al. 2010). These limitations provide some context as to why Atlantis should not be used to determine specific management rules or actions, such as setting quotas (Fulton et al. 2011; Fulton et al. 2014). Atlantis researchers and developers have continued to improve and enhance the model however, to address some of model's weaknesses and create a more cohesive user community (Weijerman et al. 2016).

Properly implemented, end-to-end models like Atlantis can provide tremendous benefits to users, including the comparison of direct, indirect, and cumulative ecosystem effects across multiple fisheries under a variety of future scenarios (Fulton et al. 2011; Kaplan et al. 2012; Weijerman et al. 2015). Atlantis has been successfully implemented in regional-scale studies around the world (Weijerman et al. 2016), at scales of up to 1.475 million $\mathrm{km}^{2}$ (Marshall 2017). These studies have demonstrated that Atlantis is a valuable tool to forecast changes in fisheries-related 
EGS resulting from drivers of ecosystem change, including pollution, fishing, and climate change (Weijerman et al. 2015; Marshall et al. 2017). The scale and scope at which this spatially explicit model can be applied is consistent with the concepts of EBM, which is relevant for ecosystems not restricted by political boundaries, and thus important to the management of coastal and estuarine EGS.

\section{InVEST Model Suite}

Coastal decision-makers must often consider different types of EGS, thus models capable of analyzing tradeoffs between different types of EGS under different scenarios are valuable in the context of coastal planning. Recently, some 'decision support tools' have been developed to aid in this process by connecting a suite of EGS models within ecological and socioeconomic frameworks (Bagstad et al. 2013b; Gret-Regamey et al. 2017). In a recent review by Ochoa and Urbina-Cardona (2017), InVEST (Integrated Valuation of Ecosystem Services and Tradeoffs), an open-source tool developed by the Natural Capital Project (NCP, www. naturalcapitalproject.org), was one of the most widely cited resources for spatially modeling EGS. InVEST was developed with the explicit purpose of integrating natural capital into decision making (Daily et al. 2009). InVEST started as a general EGS model for terrestrial and freshwater systems, but in recent years, several marine and coastal models have been incorporated into the toolset (Tallis and Polasky 2009; Guerry et al. 2012). Similar EGS decision support tools include MIMES, LUCI, and ARIES (Bagstad et al. 2013b), the latter of which is discussed in the following section.

InVEST models can be applied from the local to regional scale and provide a variety of endpoints, making them highly useful for land-use planners and other decision-makers. Most input data must be spatially explicit and can include maps of biophysical information (e.g., elevation, habitat, species distributions, etc.), as well as socio-economic indicators (e.g., population density, property values, industry costs, etc.) (Tallis and Polasky 2009; Guerry et al. 2012). Submodels use this input to predict changes in EGS such as coastal protection, fisheries, and recreation. Submodels employ several different approaches for estimating EGS, sometimes with an option to select the 'tier' of submodel (i.e., higher tiers being more complex) depending on the desired endpoints, data requirements, and effort investment (Guerry et al. 2012). Two submodels for habitat risk and water quality provide interconnections between EGS submodels and allow users to consider tradeoffs when prioritizing management across different EGS. The final submodel predicts the quantity of EGS delivered or applies valuation methods to provide monetary outputs, such as the value of sequestered carbon (Guerry et al. 2012). Individual EGS submodels can also be used independently if desired.

InVEST has been applied in many coastal planning contexts (Kim et al. 2012; Guannel et al. 2015; Oleson et al. 2017), though fewer coastal studies have taken advantage of the tool's submodel interconnections to analyze tradeoffs. The 
government of Belize partnered with the NCP in one such case study and used InVEST models to facilitate the development of an Integrated Coastal Zone Management (ICZM) plan (Arkema et al. 2015; Ruckelshaus et al. 2015; Verutes et al. 2017). With input from stakeholders and government agencies, the scientific modeling team identified three key ecosystem services (tourism, coastal protection, and the spiny lobster fishery) to analyze tradeoffs under three development scenarios. Simulating these scenarios in InVEST ultimately informed the development of an ICZM plan that was approved by the Belizean government in 2016 (Verutes et al. 2017).

The NCP continues to develop InVEST models in an on-going effort to improve connectivity with other complex models (e.g., Atlantis), enhance utility of submodels, and add new EGS models. Still, InVEST is most ideal for users with at least some spatially explicit data available from the area of interest. Gathering the spatial data required to run some of InVEST's coastal models can take considerable time and effort (e.g., see Bayani and Barthelemy 2016) and may not be feasible for all local decision makers. However, the ability to run core functions with less data and disable the more advanced model components helps to minimize this issue (Bayani and Barthelemy 2016).

\section{ARIES Model Suite}

A fundamental need to account for the spatial connectivity of ecosystem service supply and demand, with an explicit link to beneficiaries, led to development of the Artificial Intelligence for Ecosystem Services (ARIES) platform (Bagstad et al. 2013a; Villa et al. 2014a). ARIES has been refined through case studies, machinelearning, and technological advancements that now facilitates automated model customization to meet the needs of various decision makers (Villa et al. 2014a; Martínez-López et al. 2018).

As with InVEST, ARIES relies on spatially explicit input data and generates output that accounts for the location of beneficiaries, thereby closing the loop between ecological production functions that track resources (i.e., supply), to EGS of direct benefit to human users (i.e., demand) (Bagstad et al. 2013a; Villa et al. 2014a). ARIES accommodates both deterministic models and Bayesian networks to facilitate mapping of ecosystem service provision (Bagstad et al. 2014). Service Path Attribution Networks (SPANs) contain the ontologies for how services accrue in the system and are used to evaluate relationships between sources, sinks, use, and 'carriers'. Carriers are the direct link between ecosystems and people that can facilitate provisioning benefits like drinking water, or preventive benefits like floodwater (Johnson et al. 2012; Bagstad et al. 2013a; Villa et al. 2014a, b). While not explicitly an IBM like HexSim, the flow of benefits is tracked using an agent-based approach via the discretized amount of a carrier from a source, to a use region or possible sink (Villa et al. 2014a, b). Carriers can be either physical (e.g., water) or informational (e.g., aesthetic views) and underlying SPAN models that vary based 
on the type of benefit, contain the rules dictating how a carrier moves in the system, including its absorption or ultimate delivery to an end user (Johnson et al. 2012; Villa et al. 2014a). Tangible benefits result from the accumulation of carriers by beneficiaries (Bagstad et al. 2013a).

The ARIES model suite, accessible through the open source software k.LAB (Knowledge Laboratory Integrated Development Environment), includes five baseline "Tier 1" ecosystem service models (Martínez-López et al. 2018). These base models (crop pollination, flood regulation, outdoor recreation, carbon storage, and sediment regulation) can be applied anywhere in the world without any new input due to existing datasets already built into the framework. In a basic model run, the user selects the spatiotemporal context, model resolution, ecosystem service of interest, and potential scenario conditions (optional). While users with data of greater spatial or temporal resolution can get further refined output, it is not necessary (Bagstad et al. 2014; Martínez-López et al. 2018). The supply component of the models quantifies the potential provision of a benefit, but it does not necessarily capture people's decisions to utilize ecosystem services (Villa et al. 2014a). Additionally, the models for crop pollination, outdoor recreation, and flood regulation estimate demand relative to other locations, thus output reflects ranked indicators, not biophysical values (Martínez-López et al. 2018).

ARIES models have been used to evaluate multiple ecosystem services including water provision, water quality, air quality, flood regulation, climate regulation, and aesthetic views (Bagstad et al. 2014; Ochoa and Urbina-Cardona 2017). For example, Bagstad et al. (2014) used ARIES to assess how aesthetic views translated to homeowner property values in Puget Sound, Washington (USA). Source features included mountains or waterbodies that added value, whereas view obstructions or blight areas were modeled as sinks (i.e., detracting from view quality). The flow models, which included distance decay functions, computed visibility along lines of sight between use locations and sources or sinks. Final results were a ratio between the values accrued by homeowners, relative to those of the entire landscape (Bagstad et al. 2014). A web-based ARIES 'explorer' is slated for release in 2020 and should facilitate greater accessibility and subsequent application in multiple settings (Martínez-López et al. 2018). The flexibility of the k.LAB software package and integration of more data-driven models (e.g., see Willcock et al. 2018) means that ARIES is easily customizable, and a growing user community may facilitate output more tailored to coastal beneficiaries and decision-makers.

Suites of models like ARIES and InVEST that have options to model multiple EGS over space and time, have indeed proven beneficial for coastal planning (Bagstad et al. 2014; Verutes et al. 2017). The true strength of these tools is their ability to take a comprehensive look at EGS and evaluate tradeoffs between potentially competing coastal EGS (Bagstad et al. 2013b). Integrating ecosystem service considerations into the coastal planning process can provide sustained benefits to coastal communities, and tools like ARIES and InVEST enable EGS to be more readily considered (Arkema et al. 2015). The ability to visualize EGS tradeoffs in a spatial context is beneficial to communicating the importance of ecosystems to stakeholders and this may help to optimize coastal planning by aligning scientific 
research with community priorities (Bayani and Barthelemy 2016; Verutes et al. 2017).

\section{Common Difficulties, Emerging Issues, and Future Directions}

Environmental changes are occurring at an unprecedented rate within coastal and estuarine ecosystems. Models capable of predicting alterations to coastal and estuarine EGS based on changes within these dynamic systems have much to offer scientists, resource managers, and decision-makers. Though these models vary in spatial scale, quantity of EGS modeled, and complexity, they share a number of common challenges.

\subsection{Common Difficulties}

Scale is important to understanding the context and applicability of model output. The importance and relevance of coastal and estuarine EGS span across the spectrum of spatial, temporal, and governance scales (Costanza et al. 2017). Identifying the best-suited model(s) given the scale(s) of a particular question or goal is paramount in the modeling process (Carpenter et al. 2009; Turner et al. 2016), as is utilizing data that corresponds to the same scale(s). Scale-dependence is tied to the accuracy and transferability of a model-some models can be applied across multiple spatial and/or temporal scales (Boumans et al. 2015; Francesconi et al. 2016; Lewis et al. 2019), whereas others are constrained to a single place and/or time. Difficulties can arise in interpreting outputs when existing models are applied at new scales or locations, an issue that is particularly relevant to coastal ecosystems, which can span a range of spatial and temporal scales (Swaney et al. 2012). Similar difficulties occur when gathering and applying model input data from a variety of sources and scales. Upscaling and downscaling are therefore common data manipulations in EGS modeling. For instance, results from small-scale experiments or processes will often be scaled-up for use in larger-scale models because of resource constraints that limit the scope of experiments and measurements (Craft et al. 2009; Peck et al. 2016). Downscaling, on the other hand, allows coarse output from global climate or systems models to be utilized in smaller-scale models (Peck et al. 2016). In both cases, scaling the original data introduces uncertainties (Andrew et al. 2015; Cheung et al. 2016) that impact model accuracy.

Uncertainty is an inherent component of modeling that should be acknowledged by users to avoid misinterpretation of results (Bagstad et al. 2013b; Peck et al. 2016). Communication of uncertainty to community partners and stakeholders is therefore vital (Guerry et al. 2012; Ruckelshaus et al. 2015); see Fulford et al. (2020) for a 
general discussion on communicating this uncertainty as an estimation of risk. Unfortunately, this uncertainty has not often been assessed systematically in coastal and estuarine ecosystem-scale models (Weijerman et al. 2015; Cheung et al. 2016). As the scale and complexity of a model increases, so typically does the uncertainty, which can be difficult to quantify for multiple interconnected submodels. Models that project changes in biological resources based on environmental alterations are also subject to uncertainties from model parameters, model structure, internal variability, and multiple scenarios (Arkema et al. 2015; Cheung et al. 2016; Marshall et al. 2017). Monte Carlo simulations, as demonstrated by Harris et al. (2018), are one approach that can provide deterministic models with an assessment of uncertainty due to errors in input data or parameter calibration. Tools based on probabilistic frameworks that facilitate a transparent characterization of uncertainty are also gaining traction (Bryant et al. 2018; Willcock et al. 2018). Although qualitative or bounded assessments of uncertainty provide some value to users, improved methods of assessment will need to be developed to progress toward deeper understanding of the uncertainty in applications of these complex models within coastal and estuarine ecosystems (Fulton et al. 2011; Cheung et al. 2016).

The complexity, as well as the time, cost, and data requirements, of many EGS models are barriers to widespread implementation (Chan and Ruckelshaus 2010; Plaganyi et al. 2011; Bagstad et al. 2013b; Willcock et al. 2018). A tradeoff exists between the complexity required for prediction accuracy and resource (i.e., time and cost) investment (Chan and Ruckelshaus 2010), the optimal balance varies among situations (see Fulford et al. (2020) for a general discussion on the tradeoff between parsimony and realism in regard to necessary complexity). The applicability of models requiring an extensive amount of input is limited for data-poor locations (Link et al. 2010; Bayani and Barthelemy 2016; Turner et al. 2016). A model's application can also be hindered in locations with ample data if a model's input data requirements are overly stringent (Bagstad et al. 2013b). As EGS models for coastal and estuarine systems become functionally more comprehensive and complex, the expertise needed to correctly apply them can become an obstacle to implementation. Improving a model's user interface may only superficially improve its usability, which may not increase the likelihood that it is ultimately applied correctly. The inclusion of adequate model documentation will aid in the application of the model by bringing transparency to its assumptions and limitations, while also providing adequate instructions and validation exercises (Bagstad et al. 2013b).

\subsection{Emerging Issues and Future Directions}

EBM emerged as an important and effective strategy for managing natural resources and EGS, in large part because of the explicit inclusion of humans within the ecosystem (Rosenberg and McLeod 2005; Guerry et al. 2012), which has increased the complexity and difficulty in ecosystems modeling. Although many EGS models have progressed, the consideration of human benefits that are difficult to monetize 
(e.g., cultural, existence, and subsistence values) is an area that is lacking (Chan and Ruckelshaus 2010; Plaganyi et al. 2011; Guerry et al. 2012; Liquete et al. 2013; Turner et al. 2016). The breadth of user groups and social behaviors considered needs to be increased to represent socio-ecological systems more realistically (Plaganyi et al. 2011), which will include potential interactions, feedbacks, and tradeoffs between groups and uses (e.g., see Fulford et al. 2016).

There is no single model that will fit the needs of every user, nor should there be; the best model will be the one most appropriate for the situation, data, and question at hand (Plaganyi et al. 2011; Peck et al. 2016; Turner et al. 2016). To improve model relevancy and usability, resource managers and other stakeholders must be part of the model development process to identify important decision metrics (Bagstad et al. 2013b; Costanza et al. 2017) and define the most practical management alternatives to test (Fulton et al. 2014; Turner et al. 2016). Decision-makers should have models available for different uses, scales of complexity, spatial resolution, and number of services, preferably models that can be coupled (Peck et al. 2016). Searchable inventories of EGS models like the EcoService Models Library (found at https://www.epa.gov/eco-research/ecoservice-models-library) may aid managers in the initial process of selecting the appropriate one. Perhaps the most optimal solution is a modeling framework that allows users to choose which components, groups, and interactions to include, similar to the modular designs of InVEST and ARIES (Guerry et al. 2012; Bagstad et al. 2014). With some modification, these tiered or coupled models can allow for the identification and inclusion of multiple drivers and cumulative impacts on coastal and estuarine EGS, which is a critical need (Carpenter et al. 2009; Chan and Ruckelshaus 2010; Little et al. 2017).

The concept of coupling models highlights another issue-error or uncertainty from input datasets can propagate through the model and significantly affect results. Validation provides users with a measure of confidence in model output, increasing the likelihood that a model's results will be accepted and used to inform the decision process (Bagstad et al. 2013b; Andrew et al. 2015). However, the availability of suitable data to validate and inform understanding is generally lacking (Mach et al. 2015; Plaganyi et al. 2011). For instance, ecological properties or processes within EGS models have often been parameterized with coarse data (Andrew et al. 2015), whereas many satellite-based land cover datasets have not been validated at all (Song 2018). Validation of outputs from the simulation of potential future scenarios is particularly difficult as the conditions simulated may not currently exist. The EGS model comparison study by Sharps et al. (2017), demonstrates the extensive validation (utilizing measured data for flow, water quality, soil carbon, and above-ground biomass) that is ideal when applying complex EGS models such as InVEST or ARIES.

While progress continues to be made on these issues, the lack of a standardized framework for implementation may continue to limit widespread adoption of EGS models into coastal and marine planning processes (Daily et al. 2009). In recent years, scientists working with decision-makers have been developing methods to formalize the inclusion of EGS in the planning process (Arkema et al. 2015; Ruckelshaus et al. 2015). Incorporating the estimation of impacts on EGS into the 
existing framework of Environmental Impact Assessments may be a promising route (Karjalainen et al. 2013). The DPSIR (Driver, Pressure, State, Impact, Response) is another, more conceptual, framework that has shown great progress incorporating EGS in decision making (Cranford et al. 2012; Kelble et al. 2013; Elliot and O'Higgins 2020). Starting in 2015, the European interdisciplinary research project AQUACROSS developed an assessment framework for the EBM of Europe's aquatic ecosystems and applied it in eight case studies (www.aquacross.eu). As more studies demonstrate the utility of EGS modeling within ecosystem-based management situations, knowledge and experience from these cases can be used as reference to further develop these frameworks (Forst 2009). The tools provided by the growing field of EGS modeling will undoubtedly aid scientists and decisionmakers as they establish, validate, and apply innovative approaches to planning for estuarine and coastal change.

This chapter has been subjected to Agency review and has been approved for publication. The views expressed in this paper are those of the author(s) and do not necessarily reflect the views or policies of the U.S. Environmental Protection Agency.

Disclaimer This chapter has been subjected to Agency review and has been approved for publication. The views expressed in this paper are those of the author(s) and do not necessarily reflect the views or policies of the U.S. Environmental Protection Agency.

\section{References}

Andrew, M. E., Wulder, M. A., Nelson, T. A., \& Coops, N. C. (2015). Spatial data, analysis approaches, and information needs for spatial ecosystem service assessments: A review. GIScience \& Remote Sensing, 52(3), 344-373.

Arkema, K. K., Verutes, G. M., Wood, S. A., Clarke-Samuels, C., Rosado, S., Canto, M., Rosenthal, A., et al. (2015). Embedding ecosystem services in coastal planning leads to better outcomes for people and nature. Proceedings of the National Academy of Sciences, 112(24), 7390-7395. https://doi.org/10.1073/pnas.1406483112.

Bagstad, K. J., Johnson, G. W., Voigt, B., \& Villa, F. (2013a). Spatial dynamics of ecosystem service flows: A comprehensive approach to quantifying actual services. Ecosystem Services, 4, 117-125. https://doi.org/10.1016/j.ecoser.2012.07.012.

Bagstad, K. J., Semmens, D. J., Waage, S., \& Winthrop, R. (2013b). A comparative assessment of decision-support tools for ecosystem services quantification and valuation. Ecosystem Services, 5, 27-39. https://doi.org/10.1016/j.ecoser.2013.07.004.

Bagstad, K. J., Villa, F., Batker, D., Harrison-Cox, J., Voigt, B., \& Johnson, G. W. (2014). From theoretical to actual ecosystem services: Mapping beneficiaries and spatial flows in ecosystem service assessments. Ecology and Society, 19(2), 64. https://doi.org/10.5751/ES-06523-190264.

Barbier, E. B. (2016). The protective service of mangrove ecosystems: A review of valuation methods. Marine Pollution Bulletin, 109(2), 676-681. https://doi.org/10.1016/j.marpolbul. 2016.01.033.

Barbier, E. B., Hacker, S. D., Kennedy, C., Koch, E. W., Stier, A. C., \& Silliman, B. R. (2011). The value of estuarine and coastal ecosystem services. Ecological Monographs, 81(2), 169-193.

Bayani, N., \& Barthelemy, Y. (2016). Integrating ecosystems in risk assessments: Lessons from applying InVEST models in data-deficient countries. In F. G. Renaud, K. Sudmeier-Rieux, M. Estrella, \& U. Nehren (Eds.), Ecosystem-based disaster risk reduction and adaptation in practice (pp. 227-254). Cham: Springer. 
Boumans, R., Roman, J., Altman, I., \& Kaufman, L. (2015). The Multiscale Integrated Model of Ecosystem Services (MIMES): Simulating the interactions of coupled human and natural systems. Ecosystem Services, 12, 30-41. https://doi.org/10.1016/j.ecoser.2015.01.004.

Bruins, R. J. F., Canfield, T. J., Duke, C., Kapustka, L., Nahlik, A. M., \& Schafer, R. B. (2017). Using ecological production functions to link ecological processes to ecosystem services. Integrated Environmental Assessment and Management, 13(1), 52-61. https://doi.org/10. 1002/ieam.1842.

Bryant, B. P., Borsuk, M. E., Hamel, P., Oleson, K. L. L., Schulp, C. J. E., \& Willcock, S. (2018). Transparent and feasible uncertainty assessment adds value to applied ecosystem services modeling. Ecosystem Services, 33, 103-109. https://doi.org/10.1016/j.ecoser.2018.09.001.

Busch, D. S., \& McElhany, P. (2016). Estimates of the direct effect of seawater $\mathrm{pH}$ on the survival rate of species groups in the California current ecosystem. PloS One, 11(8), e0160669.

Carpenter, S. R., Mooney, H. A., Agard, J., Capistrano, D., DeFries, R. S., Díaz, S., Dietz, T., Duraiappah, A. K., Oteng-Yeboah, A., \& Pereira, H. M. (2009). Science for managing ecosystem services: Beyond the Millennium Ecosystem Assessment. Proceedings of the National Academy of Sciences, 106(5), 1305-1312.

Carr, E. W., Shirazi, Y., Parsons, G. R., Hoagland, P., \& Sommerfield, C. K. (2018). Modeling the economic value of Blue Carbon in Delaware Estuary Wetlands: Historic estimates and future projections. Journal of Environmental Management, 206, 40-50. https://doi.org/10.1016/j. jenvman.2017.10.018.

Chan, K. M., \& Ruckelshaus, M. (2010). Characterizing changes in marine ecosystem services. F1000 Biology Reports 2.

Cheung, W. L., Frölicher, T. L., Asch, R. G., Jones, M. C., Pinsky, M. L., Reygondeau, G., Rodgers, K. B., Rykaczewski, R. R., Sarmiento, J. L., Stock, C., \& Watson, J. R. (2016). Building confidence in projections of the responses of living marine resources to climate change. ICES Journal of Marine Science, 73(5), 1283-1296.

Costanza, R., d'Arge, R., De Groot, R., Farber, S., Grasso, M., Hannon, B., Limburg, K., Naeem, S., O’Neill, R. V., Paruelo, J., Raskin, R. G., Sutton, P., \& van den Belt, M. (1997). The value of the world's ecosystem services and natural capital. Nature, 387(6630), 253-260.

Costanza, R., de Groot, R., Sutton, P., Van der Ploeg, S., Anderson, S. J., Kubiszewski, I., Farber, S., \& Turner, R. K. (2014). Changes in the global value of ecosystem services. Global Environmental Change, 26, 152-158.

Costanza, R., de Groot, R., Braat, L., Kubiszewski, I., Fioramonti, L., Sutton, P., Farber, S., \& Grasso, M. (2017). Twenty years of ecosystem services: How far have we come and how far do we still need to go? Ecosystem Services, 28, 1-16.

Craft, C., Clough, J., Ehman, J., Joye, S., Park, R., Pennings, S., Guo, H., \& Machmuller, M. (2009). Forecasting the effects of accelerated sea-level rise on tidal marsh ecosystem services. Frontiers in Ecology and the Environment, 7(2), 73-78.

Cranford, P. J., Kamermans, P., Krause, G., Mazurié, J., Buck, B. H., Dolmer, P., Fraser, D., Van Nieuwenhove, K., O’Beirn, F. X., \& Sanchez-Mata, A. (2012). An ecosystem-based approach and management framework for the integrated evaluation of bivalve aquaculture impacts. Aquaculture Environment Interactions, 2(3), 193-213.

Daily, G. C., Polasky, S., Goldstein, J., Kareiva, P. M., Mooney, H. A., Pejchar, L., Ricketts, T. H., Salzman, J., \& Shallenberger, R. (2009). Ecosystem services in decision making: Time to deliver. Frontiers in Ecology and the Environment, 7(1), 21-28.

DeAngelis, D. L., \& Rose, K. A. (1992). Which individual-based based approach is most appropriate for a given problem. In D. L. DeAngelis \& L. J. Gross (Eds.), Individual-based models and approaches in ecology (pp. 67-86). London: Chapman and Hall.

Elliott, M., \& O'Higgins, T. G. (2020). From the DPSIR, the D(A)PSI(W)R(M) emerges... a butterfly-'protecting the natural stuff and delivering the human stuff'. In T. O'Higgins, M. Lago, \& T. H. DeWitt (Eds.), Ecosystem-based management, ecosystem services and aquatic biodiversity: Theory, tools and applications (pp. 61-86). Amsterdam: Springer. 
Forst, M. F. (2009). The convergence of integrated coastal zone management and the ecosystems approach. Ocean \& Coastal Management, 52(6), 294-306.

Francesconi, W., Srinivasan, R., Pérez-Miñana, E., Willcock, S. P., \& Quintero, M. (2016). Using the Soil and Water Assessment Tool (SWAT) to model ecosystem services: A systematic review. Journal of Hydrology, 535, 625-636.

Fulford, R. S., Peterson, M. S., \& Grammer, P. O. (2011). An ecological model of the habitat mosaic in estuarine nursery areas: Part I-Interaction of dispersal theory and habitat variability in describing juvenile fish distributions. Ecological Modelling, 222, 3203-3215.

Fulford, R. S., Russell, M., \& Rogers, J. E. (2016). Habitat restoration from an ecosystem goods and services perspective: Application of a spatially explicit individual-based model. Estuaries and Coasts, 39(6), 1801-1815.

Fulford, R. S., Heymans, S. J. J., \& Wu, W. (2020). Mathematical modelling for ecosystem-based management (EBM) and ecosystem goods and services (EGS) assessment. In T. O'Higgins, M. Lago, \& T. H. DeWitt (Eds.), Ecosystem-based management ecosystem services and aquatic biodiversity: Theory, tools and applications (pp. 275-290). Springer, Amsterdam.

Fulton, E. A., Link, J. S., Kaplan, I. C., Savina-Rolland, M., Johnson, P., Ainsworth, C., Horne, P., Gorton, R., Gamble, R. J., \& Smith, A. D. M. (2011). Lessons in modelling and management of marine ecosystems: The Atlantis experience. Fish and Fisheries, 12(2), 171-188.

Fulton, E. A., Smith, A. D. M., Smith, D. C., \& Johnson, P. (2014). An integrated approach is needed for ecosystem based fisheries management: Insights from ecosystem-level management strategy evaluation. PloS One, 9(1), e84242.

Gret-Regamey, A., Siren, E., Brunner, S. H., \& Weibel, B. (2017). Review of decision support tools to operationalize the ecosystem services concept. Ecosystem Services, 26, 306-315. https://doi. org/10.1016/j.ecoser.2016.10.012.

Guannel, G., Ruggiero, P., Faries, J., Arkema, K., Pinsky, M., Gelfenbaum, G., Guerry, A., \& Kim, C. K. (2015). Integrated modeling framework to quantify the coastal protection services supplied by vegetation. Journal of Geophysical Research-Oceans, 120(1), 324-345. https:// doi.org/10.1002/2014jc009821.

Guerry, A. D., Ruckelshaus, M. H., Arkema, K. K., Bernhardt, J. R., Guannel, G., Kim, C. K., Marsik, M., et al. (2012). Modeling benefits from nature: Using ecosystem services to inform coastal and marine spatial planning. International Journal of Biodiversity Science Ecosystem Services \& Management, 8(1-2), 107-121. https://doi.org/10.1080/21513732.2011.647835.

Hanson, C., Finisdore, J., \& Ranganathan, J. (2012). The Corporate Ecosystem Services Review: Guidelines for identifying business risks and opportunities arising from ecosystem change. Washington, DC: World Resources Institute.

Harris, D. L., Rovere, A., Casella, E., Power, H., Canavesio, R., Collin, A., Pomeroy, A., Webster, J. M., \& Parravicini, V. (2018). Coral reef structural complexity provides important coastal protection from waves under rising sea levels. Science Advances, 4(2). https://doi.org/10.1126/ sciadv.aao4350.

Johnson, G. W., Bagstad, K. J., Snapp, R. R., \& Villa, F. (2012). Service Path Attribution Networks (SPANs): A network flow approach to ecosystem service assessment. International Journal of Agricultural and Environmental Information Systems, 3, 54-71.

Kaplan, I. C., Horne, P. J., \& Levin, P. S. (2012). Screening California current fishery management scenarios using the Atlantis end-to-end ecosystem model. Progress in Oceanography, 102, 5-18.

Karjalainen, T. P., Marttunen, M., Sarkki, S., \& Rytkonen, A. M. (2013). Integrating ecosystem services into environmental impact assessment: An analytic-deliberative approach. Environmental Impact Assessment Review, 40, 54-64.

Kassakian, J., Jones, A., Martinich, J., \& Hudgens, D. (2017). Managing for no net loss of ecological services: An approach for quantifying loss of coastal wetlands due to sea level rise. Environmental Management, 59(5), 736-751.

Kelble, C. R., Loomis, D. K., Lovelace, S., Nuttle, W. K., Ortner, P. B., Fletcher, P., Cook, G. S., Lorenz, J. J., \& Boyer, J. N. (2013). The EBM-DPSER conceptual model: Integrating ecosystem 
services into the DPSIR framework. Plos One, 8(8), 12. https://doi.org/10.1371/journal.pone. 0070766.

Kim, C. K., Toft, J. E., Papenfus, M., Verutes, G., Guerry, A. D., Ruckelshaus, M. H., Arkema, K. K., et al. (2012). Catching the right wave: Evaluating wave energy resources and potential compatibility with existing marine and coastal uses. Plos One, 7(11), 14. https://doi.org/10. 1371/journal.pone.0047598.

Lewis, N. S., Fox, E. W., \& DeWitt, T. H. (2019). Estimating the distribution of harvested estuarine bivalves with natural-history-based habitat suitability models. Estuarine, Coastal and Shelf Science, 219, 453-472.

Link, J. S., Fulton, E. A., \& Gamble, R. J. (2010). The northeast US application of ATLANTIS: a full system model exploring marine ecosystem dynamics in a living marine resource management context. Progress in Oceanography, 87(1-4), 214-234.

Liquete, C., Piroddi, C., Drakou, E. G., Gurney, L., Katsanevakis, S., Charef, A., \& Egoh, B. (2013). Current status and future prospects for the assessment of marine and coastal ecosystem services: A systematic review. PloS One, 8(7), e67737.

Little, S., Spencer, K. L., Schuttelaars, H. M., Millward, G. E., \& Elliott, M. (2017). Unbounded boundaries and shifting baselines: Estuaries and coastal seas in a rapidly changing world. Estuarine, Coastal and Shelf Science, 198, 311-319. https://doi.org/10.1016/j.ecss.2017.10. 010.

Mach, M. E., Martone, R. G., \& Chan, K. M. A. (2015). Human impacts and ecosystem services: Insufficient research for trade-off evaluation. Ecosystem Services, 16, 112-120. https://doi.org/ 10.1016/j.ecoser.2015.10.018.

Marois, D. E., \& Mitsch, W. J. (2015). Coastal protection from tsunamis and cyclones provided by mangrove wetlands-a review. International Journal of Biodiversity Science, Ecosystem Services \& Management, 11(1), 71-83.

Marshall, K. N., Kaplan, I. C., Hodgson, E. E., Hermann, A., Busch, D. S., McElhany, P., Essington, T. E., Harvey, C. J., \& Fulton, E. A. (2017). Risks of ocean acidification in the California current food web and fisheries: Ecosystem model projections. Global Change Biology, 23(4), 1525-1539.

Martínez-López, J., Bagstad, K. J., Balbi, S., Magrach, A., Voigt, B., Athanasiadis, I., Pascual, M., Willcock, S., \& Villa, F. (2018). Towards globally customizable ecosystem service models. Science of the Total Environment, 650, 2325-2336. https://doi.org/10.1016/j.scitotenv.2018.09. 371.

Mendoza, E., Oderiz, I., Martinez, M. L., \& Silva, R. (2017). Measurements and modelling of small scale processes of vegetation preventing dune erosion. Journal of Coastal Research, 19-27. https://doi.org/10.2112/si77-003.1.

Millennium Ecosystem Assessment. (2005). Synthesis report. Island, Washington, DC.

Ochoa, V., \& Urbina-Cordona, N. (2017). Tools for spatially modeling ecosystem services: Publication trends, conceptual reflections and future challenges. Ecosystem Services, 26, 155-169. https://doi.org/10.1016/j.ecoser.2017.06.011.

Oleson, K. L. L., Falinski, K. A., Lecky, J., Rowe, C., Kappel, C. V., Selkoe, K. A., \& White, C. (2017). Upstream solutions to coral reef conservation: The payoffs of smart and cooperative decision-making. Journal of Environmental Management, 191, 8-18. https://doi.org/10.1016/j. jenvman.2016.12.067.

Pearson, S. G., Storlazzi, C. D., van Dongeren, A. R., Tissier, M. F. S., \& Reniers, A. (2017). A Bayesian-based system to assess wave-driven flooding hazards on coral reef-lined coasts. Journal of Geophysical Research-Oceans, 122(12), 10099-10117. https://doi.org/10.1002/ $2017 \mathrm{jc} 013204$.

Peck, M. A., Arvanitidis, C., Butenschön, M., Canu, D. M., Chatzinikolaou, E., Cucco, A., Domenici, P., Fernandes, J. A., Gasche, L., \& Huebert, K. B. (2016). Projecting changes in the distribution and productivity of living marine resources: A critical review of the suite of modelling approaches used in the large European project VECTORS. Estuarine, Coastal and Shelf Science, 201, 40-55. 
Plagányi, É. E. (2007). Models for an ecosystem approach to fisheries. Food and Agriculture Org. (FAO) Fisheries Technical Paper No. 477.

Plagányi, É. E., Bell, J. D., Bustamante, R. H., Dambacher, J. M., Dennis, D. M., Dichmont, C. M., Dutra, L. X. C., Fulton, E. A., Hobday, A. J., \& van Putten, E. I. (2011). Modelling climatechange effects on Australian and Pacific aquatic ecosystems: A review of analytical tools and management implications. Marine and Freshwater Research, 62(9), 1132-1147.

Pomeroy, A., Lowe, R., Symonds, G., Van Dongeren, A., \& Moore, C. (2012). The dynamics of infragravity wave transformation over a fringing reef. Journal of Geophysical ResearchOceans, 117, 17. https://doi.org/10.1029/2012jc008310.

Quataert, E., Storlazzi, C., van Rooijen, A., Cheriton, O., \& van Dongeren, A. (2015). The influence of coral reefs and climate change on wave-driven flooding of tropical coastlines. Geophysical Research Letters, 42(15), 6407-6415. https://doi.org/10.1002/2015g1064861.

Roelvink, D., Reniers, A., van Dongeren, A., de Vries, J. V., McCall, R., \& Lescinski, J. (2009). Modelling storm impacts on beaches, dunes and barrier islands. Coastal Engineering, 56 (11-12), 1133-1152. https://doi.org/10.1016/j.coastaleng.2009.08.006.

Rose, K. A., Allen, J. I., Artioli, Y., Barange, M., Blackford, J., Carlotti, F., Cropp, R., Daewel, U., Edwards, K., Flynn, K., Hill, S. L., HilleRisLambers, R., Huse, G., Mackinson, S., Megrey, B., Moll, A., Rivkin, R., Salihoglu, B., Schrum, C., Shannon, L., Shin, Y. J., Smith, S. L., Smith, C., Solidoro, C., John, M. S., \& Zhou, M. (2010). End-to-end models for the analysis of marine ecosystems: Challenges, issues, and next steps. Marine and Coastal Fisheries, 2, 115-130.

Rose, K. A., Fiechter, J., Curchitser, E. N., Hedstrom, K., Bernal, M., Creekmore, S., Haynie, A., Ito, S., Lluch-Cota, S., Megrey, B. A., Edwards, C. A., Checkley, D., Koslow, T., McClatchie, S., Werner, F., MacCall, A., \& Agostini, V. (2015). Demonstration of a fully-coupled end-toend model for small pelagic fish using sardine and anchovy in the California Current. Progress in Oceanography, 138, 348-380.

Rosenberg, A. A., \& McLeod, K. L. (2005). Implementing ecosystem-based approaches to management for the conservation of ecosystem services. Marine Ecology Progress Series, 300, 270-274.

Ruckelshaus, M., McKenzie, E., Tallis, H., Guerry, A., Daily, G., Kareiva, P., Polasky, S., et al. (2015). Notes from the field: Lessons learned from using ecosystem service approaches to inform real-world decisions. Ecological Economics, 115, 11-21. https://doi.org/10.1016/j. ecolecon.2013.07.009.

Rustigian, H. L., Santelmann, M. V., \& Schumaker, N. H. (2003). Assessing the potential impacts of alternative landscape designs on amphibian population dynamics. Landscape Ecology, 18, 65-81.

Schumaker, N. H., \& Brookes, A. (2018). HexSim: a modeling environment for ecology and conservation. Landscape Ecology, 33, 197-211.

Schumaker, N. H., Ernst, T., White, D., Baker, J., \& Haggerty, P. (2004). Projecting wildlife responses to alternative future landscapes in Oregon's Willamette Basin. Ecological Applications, 14, 381-400.

Sharps, K., Masante, D., Thomas, A., Jackson, B., Redhead, J., May, L., Prosser, H., Cosby, B., Emmett, B., \& Jones, L. (2017). Comparing strengths and weaknesses of three ecosystem services modelling tools in a diverse UK river catchment. Science of the Total Environment, 584, 118-130. https://doi.org/10.1016/j.scitotenv.2016.12.160.

Sheppard, C., Dixon, D. J., Gourlay, M., Sheppard, A., \& Payet, R. (2005). Coral mortality increases wave energy reaching shores protected by reef flats: Examples from the Seychelles. Estuarine, Coastal and Shelf Science, 64(2-3), 223-234. https://doi.org/10.1016/j.ecss.2005. 02.016.

Song, X.-P. (2018). Global estimates of ecosystem service value and change: Taking into account uncertainties in satellite-based land cover data. Ecological Economics, 143, 227-235.

Swaney, D. P., Humborg, C., Emeis, K., Kannen, A., Silvert, W., Tett, P., Pastres, R., et al. (2012). Five critical questions of scale for the coastal zone. Estuarine, Coastal and Shelf Science, 96, 9-21. https://doi.org/10.1016/j.ecss.2011.04.010. 
Tallis, H., \& Polasky, S. (2009). Mapping and valuing ecosystem services as an approach for conservation and natural-resource management. In R. S. Ostfeld \& W. H. Schlesinger (Eds.), Year in ecology and conservation biology (pp. 265-283). Blackwell Publishing, Oxford: Annals of the New York Academy of Sciences.

Travers, M., Shin, Y. J., Jennings, S., \& Cury, P. (2007). Towards end-to-end models for investigating the effects of climate and fishing in marine ecosystems. Progress in Oceanography, 75(4), 751-770.

Turner, K. G., Anderson, S., Gonzales-Chang, M., Costanza, R., Courville, S., Dalgaard, T., Dominati, E., et al. (2016). A review of methods, data, and models to assess changes in the value of ecosystem services from land degradation and restoration. Ecological Modelling, 319, 190-207. https://doi.org/10.1016/j.ecolmodel.2015.07.017.

Van Dongeren, A., Lowe, R., Pomeroy, A., Trang, D. M., Roelvink, D., Symonds, G., \& Ranasinghe, R. (2013). Numerical modeling of low-frequency wave dynamics over a fringing coral reef. Coastal Engineering, 73, 178-190. https://doi.org/10.1016/j.coastaleng.2012.11. 004.

Verutes, G. M., Arkema, K. K., Clarke-Samuels, C., Wood, S. A., Rosenthal, A., Rosado, S., Canto, M., Bood, N., \& Ruckelshaus, M. (2017). Integrated planning that safeguards ecosystems and balances multiple objectives in coastal Belize. International Journal of Biodiversity Science Ecosystem Services \& Management, 13(3), 1-17. https://doi.org/10.1080/21513732.2017. 1345979.

Villa, F., Bagstad, K. J., Voigt, B., Johnson, G. W., Portela, R., Honzak, M., \& Batker, D. (2014a). A methodology for adaptable and robust ecosystem services assessment. PloS One, 9(3), e91001.

Villa, F., Voigt, B., \& Erickson, J. D. (2014b). New perspectives in ecosystem services science as instruments to understand environmental securities. Philosophical Transactions of the Royal Society B, 369, 20120286. https://doi.org/10.1098/rstb.2012.0286.

Weijerman, M., Fulton, E. A., Kaplan, I. C., Gorton, R., Leemans, R., Mooij, W. M., \& Brainard, R. E. (2015). An integrated coral reef ecosystem model to support resource management under a changing climate. PloS One, 10(12), e0144165.

Weijerman, M., Link, J. S., Fulton, E. A., Olsen, E., Townsend, H., Gaichas, S., Hansen, C., SkernMauritzen, M., Kaplan, I. C., \& Gamble, R. (2016). Atlantis Ecosystem Model Summit: Report from a workshop. Ecological Modelling, 335, 35-38.

Willcock, S., Martínez-López, J., Hooftman, D. A. P., Bagstad, K. J., Balbi, S., Marzo, A., Prato, C., Sciandrello, S., Signorello, G., Voigt, B., Villa, F., Bullock, J. M., \& Athanasiadis, I. N. (2018). Machine learning for ecosystem services. Ecosystem Services, 33, 165-174. https://doi. org/10.1016/j.ecoser.2018.04.004.

Open Access This chapter is licensed under the terms of the Creative Commons Attribution 4.0 International License (http://creativecommons.org/licenses/by/4.0/), which permits use, sharing, adaptation, distribution and reproduction in any medium or format, as long as you give appropriate credit to the original author(s) and the source, provide a link to the Creative Commons licence and indicate if changes were made.

The images or other third party material in this chapter are included in the chapter's Creative Commons licence, unless indicated otherwise in a credit line to the material. If material is not included in the chapter's Creative Commons licence and your intended use is not permitted by statutory regulation or exceeds the permitted use, you will need to obtain permission directly from the copyright holder. 